\title{
A Retrospective Study of Dental Changes after Facial Contouring Surgery
}

Jong Chul Park ( $\square$ vvsaz144@daum.net)

Wonjin Dental and Plastic Clinic

\section{Research Article}

Keywords: contouring surgery, later growth, dental change, occlusion, extrusion, angle reduction, zygoma reduction

Posted Date: September 21st, 2020

DOl: https://doi.org/10.21203/rs.3.rs-81155/v1

License: (9) This work is licensed under a Creative Commons Attribution 4.0 International License. Read Full License 


\section{Abstract}

Background: The purpose of this study was to confirm whether long-term dental changes after people were aged beyond their 20s would be affected by undergoing facial contouring surgery, such as angle and zygoma reduction. Additionally, we intended to verify whether these changes would be significantly different depending on the type of contouring surgery.

Methods: We included 77 subjects who underwent contouring surgery from December 13,2011 , to December 3, 2018. Of these subjects, 73 were female, and 5 were male. We followed up with these patients from 11 to 82 months after surgery. The average follow-up period was 33.6 months. The age at surgery was 18 to 48 years old. The average age was 29.5 years old. To assess dental changes, we measured variables such as the extrusion of a maxillary anterior and posterior tooth, angle from point $A$ to nasion to point $\mathrm{B}\left(\mathrm{ANB}^{\circ}\right)$ change, and overjet/overbite change between pre- and postoperative periods using computed tomography.

Results: There was a positive linear correlation between the extrusion of the maxillary teeth and the follow-up period. The correlation coefficients of incisors and molars were 0.454 and 0.461 , respectively ( $p$ $=0.000$ for incisors and 0.000 for molars). With age, there was also a negative correlation in extrusion. The correlation coefficient was -0.442 for incisors and -0.394 for molars $(p=0.000$ for incisors and 0.000 for molars). We also confirmed significant differences in incisor extrusion and $\mathrm{ANB}^{\circ}$ change depending on the type of surgery $\left(p=0.018\right.$ for incisor extrusion and 0.003 for $\left.A N B^{\circ}\right)$.

Conclusion: We observed dental changes in subjects who underwent facial contouring surgery, and these changes were affected by the type of operation.

\section{Background}

Maxillofacial surgeons generally assumed that patients' growth does not continue to change when performing facial contouring surgeries after a person is aged beyond their $20 \mathrm{~s}$. The authors have also established a surgical plan on the premise that tooth movement and facial contour surgery are not related. However, since 2011, the authors have performed computed tomography (CT) analysis of all patients before and after contouring surgery. Most of the patients who underwent follow-up (F/U) observations for more than six months were able to confirm tooth extrusion regardless of orthodontic treatment. Therefore, the authors reviewed the literature to confirm whether this was caused by surgery or a physiological phenomenon.

Until the mid-20th century, scientists had thought that growth stopped after puberty. However, studies using a cephalometric X-ray reported that growth continues in adulthood [1-5]. They revealed that the facial bones become longer after a person is aged beyond their 20s. They also found maxillary teeth extrusion and posterior rotation of the mandible in women. Other studies have also reported that these changes are related to changes in the dentoalveolar complex [2, 6-9]. 
However, no studies have proven whether dental changes are prevented or promoted by facial contouring surgery. Therefore, this study aimed to confirm whether a later dental change occurring after a person is aged beyond their 20 s would also be found in subjects who underwent facial contouring surgery.

The authors were also able to review the studies showing that mandibular angle surgery can affect masticatory muscle, and occlusal changes occur when Botox is injected $[10,11]$. Thus, compared to the cases in which zygoma surgery or angle surgery were performed individually, when the surgeries are performed simultaneously, it is assumed that masticatory muscles such as masseter muscle or temporal muscle would be more greatly affected. Hence, we tried to determine if there was a difference in dental changes between the groups.

\section{Methods}

\section{Study design and sample}

Patient selection - All the patients in this study had undergone facial contouring surgery, such as angle reduction, zygoma reduction, and genioplasty. They underwent the operation between December 13, 2011, and December 3, 2018. Among the patients, we enrolled 89 subjects who had F/U sessions 11 months after surgery or later with pre- and postoperative CT images. Among the subjects, we kept the exclusion criteria as follows: 1 . if he/she had a maxillary incisor or molar prosthesis that distorted the CT image, 2. if he/she had undergone orthodontic treatment during the postoperative F/U period, 3. if he/she had resorption of the condyle, and 4 . if he/she had undergone a revision operation.

As a result, we included 77 patients in this study. Of these subjects, 72 were female, and 5 were male. All study protocols were approved by the Public Institutional Bioethics Committee (P01-202006-21-029). The study was performed according to the Declaration of Helsinki guidelines on experimentation involving human subjects.

\section{Independent variables}

Table 1 shows the type of surgery, the number of cases, the age at the operation, and the observation period for each surgery. To evaluate the effect of contouring surgery on dental changes, we compared two surgery groups: one group (group 1) had undergone angle and zygoma surgery simultaneously. The other group (group 2) underwent only one operation for angle and zygoma reduction or underwent genioplasty without angle and zygoma surgery (Table 2). All male patients belonged to group 1.

Table 1 The age at the operation and observation period according to the type of surgery 


\begin{tabular}{|c|c|c|c|c|c|}
\hline \multirow[t]{2}{*}{ Operation } & \multirow[t]{2}{*}{ Case } & \multicolumn{2}{|c|}{ Age at operation (year) } & \multicolumn{2}{|c|}{ Observation period (month) } \\
\hline & & Mean & Max min & Mean & Max min \\
\hline Angle & 3 & 29.6 & $18-46$ & 24.3 & $13-37$ \\
\hline Zygoma & 8 & 35.1 & $24-47$ & 26.0 & $12-66$ \\
\hline Genio & 1 & 22.9 & 22.95 & 55.0 & 55 \\
\hline Angle + zygoma & 18 & 29.9 & $19-48$ & 29.9 & $11-72$ \\
\hline Angle + genio & 5 & 27.8 & $18-46$ & 54.6 & $15-80$ \\
\hline Zygoma + genio & 1 & 32.9 & 33 & 28.0 & 28 \\
\hline Angle + genio + zygoma & 41 & 28.5 & $19-48$ & 34.4 & $11-82$ \\
\hline Total & 77 & 29.5 & $18-48$ & 33.6 & $11-82$ \\
\hline
\end{tabular}

Angle: angle reduction, zygoma: zygoma reduction, genio: genioplasty

Table 2 Comparison of age at operation and during the observation period between the two surgery groups

\begin{tabular}{|lccccc|}
\hline Operation & Frequency & \multicolumn{2}{c|}{$\begin{array}{l}\text { Age at operation } \\
\text { (year) }\end{array}$} & \multicolumn{3}{l|}{$\begin{array}{l}\text { Observation period } \\
\text { (months) }\end{array}$} \\
& & Mean & $\begin{array}{l}\text { Max } \\
\text { min }\end{array}$ & Mean & Max min \\
\hline $\begin{array}{l}\text { Group 1 (angle and zygoma surgery at the } \\
\text { same time) }\end{array}$ & 59 & 28.9 & $19-48$ & 33.1 & $11-82$ \\
\hline Group 2 (the other types of surgery) & 18 & 31.3 & $18-47$ & 35.4 & $12-80$ \\
\hline Total & 77 & 29.5 & $18-48$ & 33.6 & $11-82$ \\
\hline
\end{tabular}

Group 1 underwent angle and zygoma surgery at the same time. Group 2 underwent only one surgery for angle and zygoma reduction or underwent genioplasty without angle and zygoma surgery.

\section{Dependent variable}

To assess dental changes, we measured variables such as the extrusion of a maxillary anterior and posterior tooth, the angle from point $A$ to nasion to point $B\left(A N B^{\circ}\right)$ change, and the overbite $(O B)$ /overjet $(\mathrm{OJ})$ change between the pre- and postoperative periods. Of the 77 patients, we did not measure molar extrusion in one patient who lost six posterior teeth. We also excluded five patients with dual bites from $\mathrm{ANB}^{\circ}$ and $\mathrm{OB} / \mathrm{OJ}$ measurements. 
CT scans were performed using cone-beam CT (Alphard-3030, ASAHI ROENTGEN, Kyoto, Japan) at the habitual intercuspal position. We used C-mode to obtain an adequate exposure area. The data were processed using InVivoDental 3D imaging software (Anatomage, Inc., San Jose, CA). In the superimposition view, we opened the pre- and postoperative scans concurrently and superimposed them. In the sagittal plane, we measured the extrusion of the maxillary incisor, the change in ANB degree, and the OB/OJ ratio. Fig. 1 shows how these variables were measured. If the sagittal plane overlapped the interproximal space of the maxillary incisor, we moved the reference plane to the incisal tip. With this adjustment, we measured the extrusion of the incisor. When the tooth was extruded, we assigned it a positive value. In the coronal plane, we measured the extrusion of the distal buccal cusp of the first maxillary molar. We averaged the change of both sides (Fig. 2).

\section{Reliability of the measurements}

The cross-sectional CT image was enlarged to a predetermined size and measured twice using a length measuring instrument embedded in the InVivoDental program. The CT image was viewed at 5x magnification during measurements (adjusted so that the scale bar of $2 \mathrm{~cm}$ on display is $10 \mathrm{~cm}$ for the actual ruler). We repeated the analysis until the value of two successive measurements had a discrepancy error less than $0.2 \mathrm{~mm}$ or 0.2 degrees.

\section{Statistical analysis}

The descriptive statistics of the pre- and postoperative measurements were processed using the SPSS for Windows version 21 software program (IBM Corp., Armonk, NY). The normality test (KolmogorovSmirnov) was performed for all variables. Accordingly, we selected parametric ( $T$ test) or nonparametric (Mann-Whitney U test) methods to compare the differences between the groups. To confirm the correlation between the variables, we chose parametric (Pearson) or nonparametric analysis (Spearman) as appropriate. If normality and equality of variance were verified, we performed an analysis of covariance (ANCOVA) using age and period as covariates. Differences were considered to be significant at $p<0.05$.

\section{Results}

\section{The pattern of dental change after contouring surgery}

There was a positive linear correlation between the extrusion of the maxillary teeth (both incisors and molars) and the F/U period (Fig. 3). The correlation coefficients of incisors and molars were 0.454 and 0.461 , respectively. When the F/U period was less than 18 months, the extrusion of the maxillary incisor and molar was $0.19 \mathrm{~mm}$, but when the patient was observed for more than 55 months, the amount increased to $0.62 \mathrm{~mm}$ in the incisor and $0.55 \mathrm{~mm}$ in the molar. 
There was also a negative linear correlation between the extrusion of the maxillary teeth and the age at surgery (Fig. 4). When we operated on subjects under 22 years old, the extrusion of the maxillary incisor and molar was $0.54 \mathrm{~mm}$. When the subjects underwent surgery after 36 years of age, the amount of extrusion was only $0.21 \mathrm{~mm}$ for the incisor and $0.19 \mathrm{~mm}$ for the molars. The correlation coefficient was -0.442 for incisors and -0.394 for molars. Age at surgery and $O B$ also showed a significant negative correlation (correlation coefficient $=-0.279$ ). We confirmed that the longer the F/U period, the higher the amount of extrusion, and the younger the surgery, the higher the amount of extrusion.

\section{Differences in dental change according to the combination of surgery type}

We performed three kinds of surgery: angle reduction, zygoma reduction, and genioplasty. According to how these three surgeries were combined, one patient could undergo one of seven surgery types (Table 1). To check if there is a statistically significant difference according to these surgery types, we grouped patients in various ways based on surgery type. As a result, we confirmed the statistically significant difference between the two groups (Table 2).

We analyzed the differences with the Mann-Whitney $U$ test in the age that the patient underwent surgery and the period between the two groups, but no significant differences were identified ( $p=0.572$ for age, 0.641 for the period) (Table 2). In group 1, we found incisor extrusion by $0.43 \mathrm{~mm}$ and molar extrusion by $0.34 \mathrm{~mm}$. In group 2, these values were increased by $0.19 \mathrm{~mm}$ and $0.25 \mathrm{~mm}$, respectively. The ANB ${ }^{\circ}$ increased by $0.31^{\circ}$ in group 1 and $0.09^{\circ}$ in group 2 . We found statistically significant differences in the variables $\left(p=0.018\right.$ for incisor and 0.003 for $\left.\mathrm{ANB}^{\circ}\right)($ Table 3$)$.

Table 3 Differences in dental changes according to the type of surgery

\begin{tabular}{|c|c|c|c|c|c|c|c|}
\hline & \multicolumn{3}{|c|}{ Group 1} & \multicolumn{3}{|c|}{ Group 2} & \multirow[t]{2}{*}{$p$ value $^{*}$} \\
\hline & $\mathrm{N}$ & Mean & SD & $N$ & Mean & SD & \\
\hline Incisor & 59 & 0.43 & 0.38 & 18 & 0.19 & 0.18 & $0.018^{a}$ \\
\hline Molar & 58 & 0.34 & 0.28 & 18 & 0.25 & 0.19 & $0.214^{\mathrm{a}}$ \\
\hline ANB & 55 & 0.31 & 0.24 & 17 & 0.09 & 0.26 & $0.003^{a}$ \\
\hline ANB & 55 & 0.31 & 0.24 & 17 & 0.09 & 0.26 & $0.003^{a}$ \\
\hline OJ & 55 & 0.16 & 0.38 & 17 & -0.01 & 0.47 & $0.309^{a}$ \\
\hline OB & 55 & 0.04 & 0.41 & 17 & -0.12 & 0.58 & $0.197^{b}$ \\
\hline
\end{tabular}

* $P$ value $<0.05$ was considered statistically significant, ${ }^{a} P$ value was calculated by Mann-Whitney $U$ test, ${ }^{b} \mathrm{P}$ value was calculated by $\mathrm{t}$ test. Incisor the amount of maxillary incisor extrusion. When the incisor was extruded, we assigned it a positive value. Molar: the amount of maxillary molar extrusion. $A N B$ was 
calculated by subtracting the pre-ANB ${ }^{\circ}$ from the post-ANB ${ }^{\circ}$. $O J$ was calculated by subtracting pre-overjet from post-overjet. $O B$ was calculated by subtracting pre-OB from post-OB

\section{Discussion}

This study is the first to verify long-term dental changes after contouring surgery by CT imaging. For this reason, it is necessary to prove whether this phenomenon is due to surgery or physiological responses to growth that can occur regardless of whether a person has a contouring operation.

Since the mid-20th century, scientists have accepted the concept of growth as the entire series of anatomical and physiological changes taking place between the beginning of prenatal life and becoming elderly [4]. Akgül et al. [9] said that this phenomenon favors the term change by aging or maturational process over the term growth because it includes not only an increase in dimension but also a decrease. In this study, we chose the term dental change to describe the net result of dentoalveolar changes according to the progression of time regardless of the cause, whether iatrogenic or physiologic.

Many studies have reported that dental changes occur in adults without surgery or orthodontic treatment. Bondevik reported dental changes from ages 23 to 34 in subjects who did not receive any treatment [12]. Bishara et al. [1] also observed changes in untreated samples between the ages of 25 and 46 . With a cephalogram, they confirmed the change in $\mathrm{ANB}^{\circ}$ as measured as $0.58 \pm 0.63^{\circ}$ in women [1]. We verified that the direction of change was the same as that observed in their study. Our data showed that the change in $\mathrm{ANB}^{\circ}$ was $0.31 \pm 0.24^{\circ}$ in group 1 and $0.09 \pm 0.26^{\circ}$ in group 2 . However, there were significant differences in the amount of change between the surgery groups $(p=0.003)$.

Forsberg et al. [3] also observed skeletal changes in adulthood between the ages of 24 and 34 and assured posterior rotation of the mandible and an adjustment of the upper incisors to the new lower jaw position. During the first five years, the maxillary incisor increased vertically by $0.34 \mathrm{~mm}$. The change was less than that of group $1(0.43 \mathrm{~mm})$ and more than that of group $2(0.19 \mathrm{~mm})$ in our study. They did not measure $\mathrm{ANB}^{\circ}$. Instead, the mandibular line (a tangent to the lower posterior border of the mandible through the gnathion) was measured, and over five years, measurements in females increased by $0.35^{\circ}$ but by $0.17^{\circ}$ for the next five years.

Pecora et al. [5] analyzed craniofacial growth changes between the ages of 17,47 , and 57 years. They found that the anterior cranial base length increased by $1.6 \mathrm{~mm}$ from 17 to 47 years of age, and the nasion moved anteriorly. They reported that the maxillary teeth extruded by $0.3 \mathrm{~mm}$. Both the length from the condylion to point $A$ and the length from the condylion to the gnathion increased. The length in males increased by $4.1 \mathrm{~mm}$, and that in females increased by $1.8 \mathrm{~mm}$. Because of this, women had more vertical changes with posterior rotation of the mandible [5]. Therefore, $\mathrm{ANB}^{\circ}$ increased by $0.7^{\circ}$ in women up to the age of 47 and no increase was observed in men. The increase in ANB ${ }^{\circ}$ in our study also seemed to be related to the fact that only 5 out of 77 subjects were males, especially in group $1\left(0.31^{\circ}\right)$. In all five subjects, the $\mathrm{ANB}^{\circ}$ changed less than the average ( $0.26^{\circ}$ for males, $0.32^{\circ}$ for females). However, in group 2 , although all subjects were female, the change in $\mathrm{ANB}^{\circ}$ was minimal. 
Choi et al. [2] observed a change in the craniofacial complex and alveolar bone height for Asian females over four years with a lateral cephalogram. The length from the nasal floor to the incisal tip and from the nasal floor to the molar cusp increased by $0.7 \mathrm{~mm}$ and $0.6 \mathrm{~mm}$, respectively, over four years [2]. In our study, extrusion of the incisor and molar between 43 and 54 months, corresponding to 4 years, was 0.57 and $0.46 \mathrm{~mm}$, respectively. They reported that the $A N B^{\circ}$ increased by $0.5^{\circ}$ over four years. In our study, the $\mathrm{ANB}^{\circ}$ increased by $0.33^{\circ}$ from 43 to 54 months. Overall, our research showed less change than that observed by Choi et al. [2] Whether this difference is due to an intervention in the physiological change induced by surgery or a cephalography measurement error making it inferior to CT analysis, more research is needed. However, the fact that the data in group 1 show more changes compared to the data in group 2 leads to the inference that surgery may not hinder physiological change; rather, surgery can exaggerate it.

Through a review of the above papers, we found that the extrusion of maxillary teeth and the increase in ANB observed may be related to a later dental change in physiological phenomena. However, we also found significant differences according to the type of surgery. The dentofacial change was physiologic, but contouring surgery might influence the result. Therefore, we need to clarify how contouring surgery induces differences in physiological changes.

Song et al. [10] have reported that alteration in bite force can lead to occlusal changes. They found that injecting Botox into both masseter muscles not only weakens muscle strength but also changes occlusion . Lo et al. [11] also reported that ostectomy of the mandibular angle could cause masseter muscle atrophy even without muscle resection. However, whether the decrease in volume correlates with the decrease in bite force has not been proven. There is a study that angle reduction does not affect the biting force between the period before the operation and six months afterward [13].

Tooth eruption may occur throughout one's whole life to compensate for occlusal surface wear $[7,14]$. This eruption may cause an open bite when there is no masticatory force strong enough to cause erosion of the teeth or to resist the eruption force. Therefore, although Tan et al. [13] reported no reduction in bite force after angle reduction surgery only, it may be estimated that there would be more reduction in bite force when the patient underwent angle and zygoma reduction simultaneously. However, to prove this, more research on the reduction of bite force after contouring surgery should be conducted.

We also focused on the physiological adaptation in which atrophic muscles return to their original length. In orthognathic surgery, maxillofacial surgeons have considered ramal inclination as a vital factor for postoperative dental change. When the ramus rotates clockwise, the muscle length becomes more extended, and relapse occurs due to physiological action that prompts it to return to the original length [15]. This reasoning may also be applied to contouring surgery. If the muscle atrophied due to the surgery, the muscle length would be shortened, and the physiological tendency to return to the original length would rotate the mandible clockwise. To adapt to this new mandible position, the alveolar process may extrude the teeth. 
The advantage of using CT images to check dental changes over a lateral cephalogram is that the CT images can more accurately identify the differences through the superimposed data embedded in the 3D image software, rather than requiring $\mathrm{X}$-rays of two periods to be traced to measure the amount of change. When measured by cephalogram, the error is more than $0.5 \mathrm{~mm}$, so it is less accurate when analyzed using CT [16]. In addition, we can exclude the measuring error of the ANB $^{\circ}$ due to the dual bite. In this study, we can see the discrepancy of the condylar position before and after an operation in 5 subjects, and we excluded these subjects from $\mathrm{ANB}^{\circ}, \mathrm{OJ}$, and $\mathrm{OB}$ analysis. It is also possible to check whether the joints were absorbed with the $\mathrm{CT}$ images, but we could not find condylar resorption during the study period in the subjects included in our study.

There are some limitations to this study. As a retrospective study, it does not have the impact of a randomized controlled trial. In addition, the F/U period was not constant. It seems that the amount of extrusion and the postoperative period are correlated. Therefore, more research is needed to exclude the effect of the postoperative period on our results. Therefore, more research is needed to evaluate the effect of horizontal movement on tooth extrusion.

\section{Conclusions}

1. This study investigated long-term dental changes after facial contouring surgery using cone-beam CT for the first time.

2. We found tooth extrusion after facial contouring surgery.

3. The type of facial contouring surgery affected the amount of extrusion and the change in the $\mathrm{ANB}^{\circ}$.

\section{Declarations}

\section{Ethics approval and consent to participate}

This study was approved by the Public Institutional Bioethics Committee (P01-202006-21-029)

\section{Consent for publication}

This manuscript does not contain any individual person's identifier

\section{Availability of data and materials}

\section{Competing interests}

The authors declare that they have no competing interests

\section{Funding}

This study received no specific grant from any funding agency in the public, commercial, or not-for-profit sectors 
Authors' contributions

$\mathrm{JC}$ carried out the measurement, analyzed the data, and wrote the manuscripts.

\section{Acknowledgements}

This work was not supported by any fund or person

\section{Authors' information}

Wonjin dental clinic, Pagoda Tower 17th floor 1306-6 Seocho-dong Seocho-gu, Seoul

\section{References}

1. Bishara SE, Treder JE, Jakobsen JR (1994) Facial and dental changes in adulthood. Am J Orthod Dentofacial Orthop 106:175-186.

2. Choi SH, Jung SN, Cha JY et al. (2016) Changes in the craniofacial complex and alveolar bone height of young adults: applications to dental medicine. Clin Anat 29:1011-1017.

3. Forsberg CM (1979) Facial morphology and ageing: a longitudinal cephalometric investigation of young adults. Eur $\mathrm{J}$ Orthod 1:15-23.

4. Meredith HV (1945) Toward a working concept of physical growth. Am J Orthod Oral Surg 31:440458.

5. Pecora NG, Baccetti T, McNamara JA (2008) The aging craniofacial complex: a longitudinal cephalometric study from late adolescence to late adulthood. Am J Orthod Dentofacial Orthop 134:496-505.

6. Forsberg CM, Eliasson S, Westergren $\mathrm{H}$ (1991) Face height and tooth eruption in adults-a 20-year follow-up investigation. Eur J Orthod 13:249-254.

7. Murphy $T$ (1959) Compensatory mechanisms in facial height adjustment to functional tooth attrition. Aust Dent J 4:312-323.

8. Sinclair PM, Little RM (1983) Maturation of untreated normal occlusions. Am J Orthod 83:114-123.

9. Akgül AA, Toygar TU (2002) Natural craniofacial changes in the third decade of life: a longitudinal study. Am J Orthod Dentofacial Orthop 122:512-522.

10. Song JH, Cho ES, Kim ST, Ahn HJ (2014) Change of distribution and timing of bite force after botulinum toxin type A injection evaluated by a computerized occlusion analysis system. Yonsei Med J 55:1123-1129.

11. Lo LJ, Mardini S, Chen YR (2005) Volumetric change of the muscles of mastication following resection of mandibular angles: a long-term follow-up. Ann Plast Surg 54:615-621; discussion 622.

12. Bondevik $O$ (1998) Changes in occlusion between 23 and 34 years. Angle Orthod 68:75-80.

13. Tan W, Gui L, Wang M et al. (2010) Changes in occlusal force after intraoral one-stage curved osteotomy of the prominent mandibular angle. Aesthetic Plast Surg 34:330-334. 
14. Newman HN (1999) Attrition, eruption, and the periodontium. J Dent Res 78:730-734.

15. Proffit WR, Turvey TA, Phillips $C$ (2007) The hierarchy of stability and predictability in orthognathic surgery with rigid fixation: an update and extension. Head Face Med 3:21.

16. de Bernabé PG, Montiel-Company JM, Paredes-Gallardo V, Gandía-Franco JL, Bellot-Arcís C (2017) Orthodontic treatment stability predictors: a retrospective longitudinal study. Angle Orthod 87:223229.

\section{Figures}

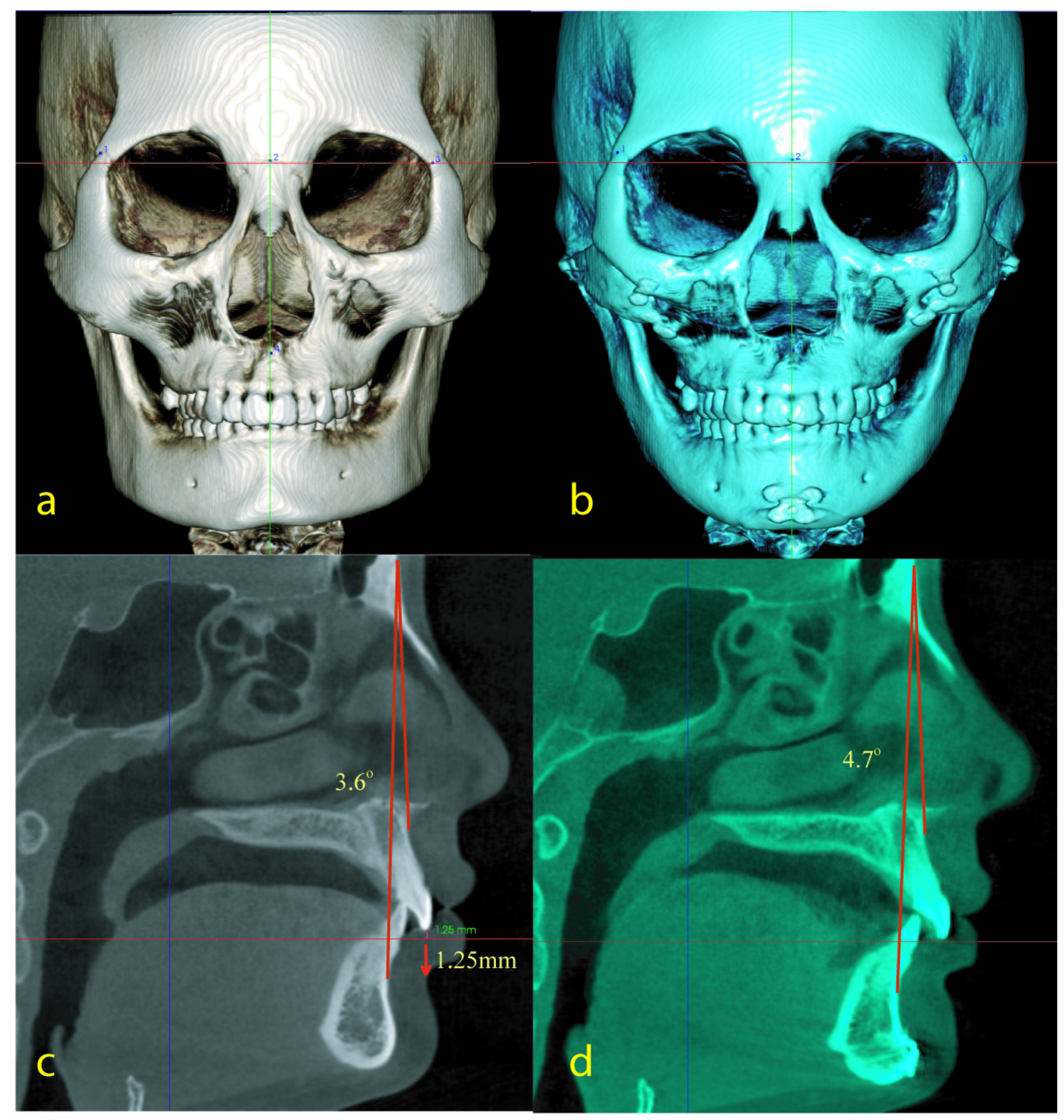

Figure 1 
Measurement of the extrusion of the maxillary incisor and the change in $\mathrm{ANB}^{\circ}$. $\mathrm{ANB}^{\circ}$, angle from point $A$ to nasion to point B. Point A, the deepest anterior point in the concavity of the anterior maxilla. Point $B$, the deepest anterior point in the concavity of the anterior mandible. a: Preoperative skeletal 3D image. b: Postoperative skeletal 3D image. c: Preoperative sagittal view. The numbers in green are the real measurement values by InVivoDental software. To clearly show the value, we magnified the number and displayed it in yellow. The head of the red arrow indicates the direction of the postoperative change. D: Postoperative sagittal view.

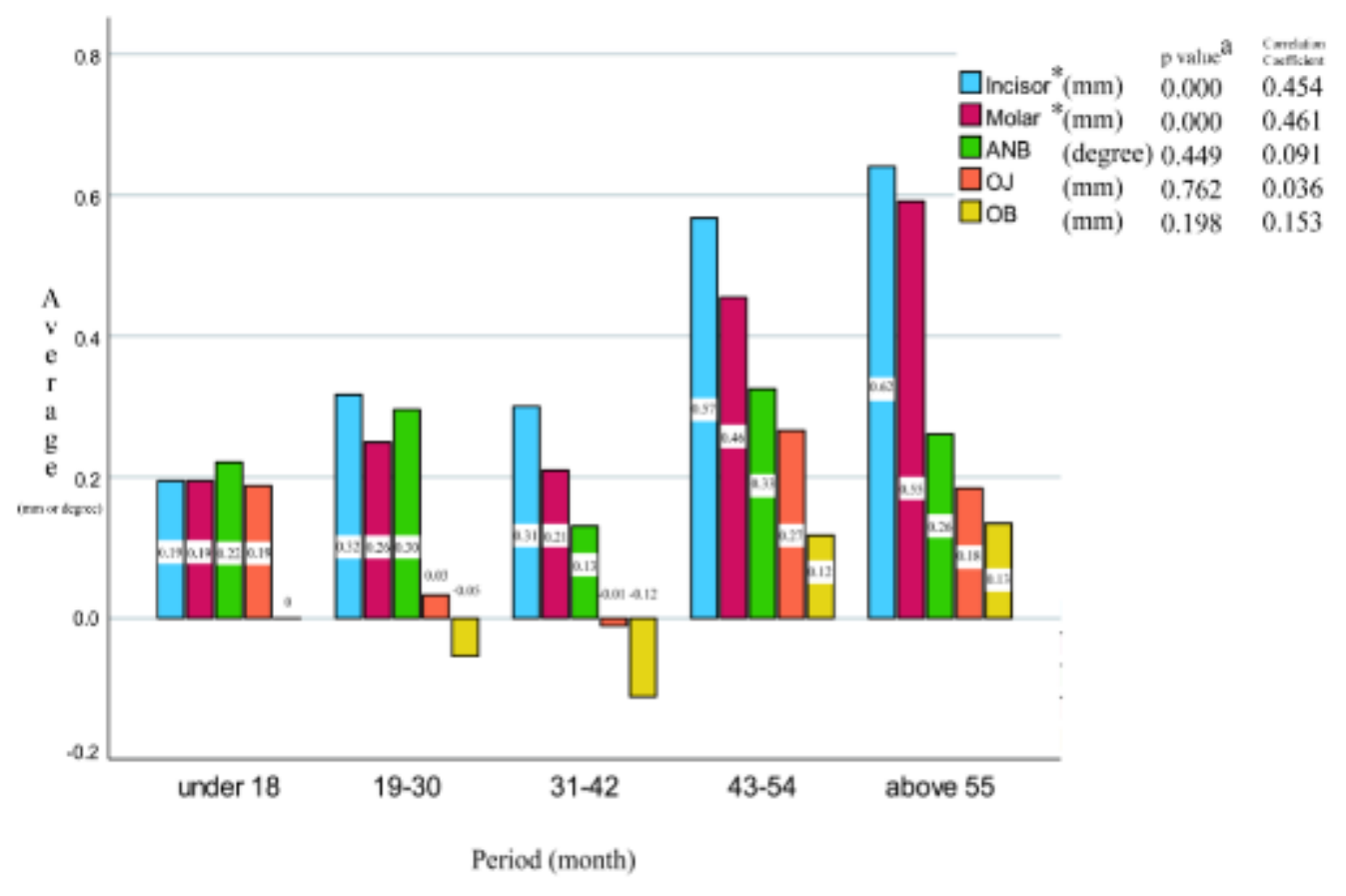

Figure 2

The correlation between the variables and the final follow-up period after the operation. Incisor, the amount of maxillary incisor extrusion. When the incisor was extruded, we assigned it a positive value. Molar, the amount of maxillary molar extrusion. ANB, calculated by subtracting the pre-ANB ${ }^{\circ}$ from the post-ANB ${ }^{\circ}$. OJ, calculated by subtracting the pre-overjet value from the post-overjet value. OB, calculated by subtracting pre-overbite value from the post-overbite value. Overjet, the distance between the maxillary incisor and most labial and mandibular incisor edges parallel to the occlusal plane. Overbite, the distance between the maxillary incisor edge and mandibular incisor edge perpendicular to the occlusal plane. We confirmed a significant correlation with the period for both incisor and molar. * $p$ value $<0.05$ was considered statistically significant. The $p$ value was calculated by Spearman analysis. 


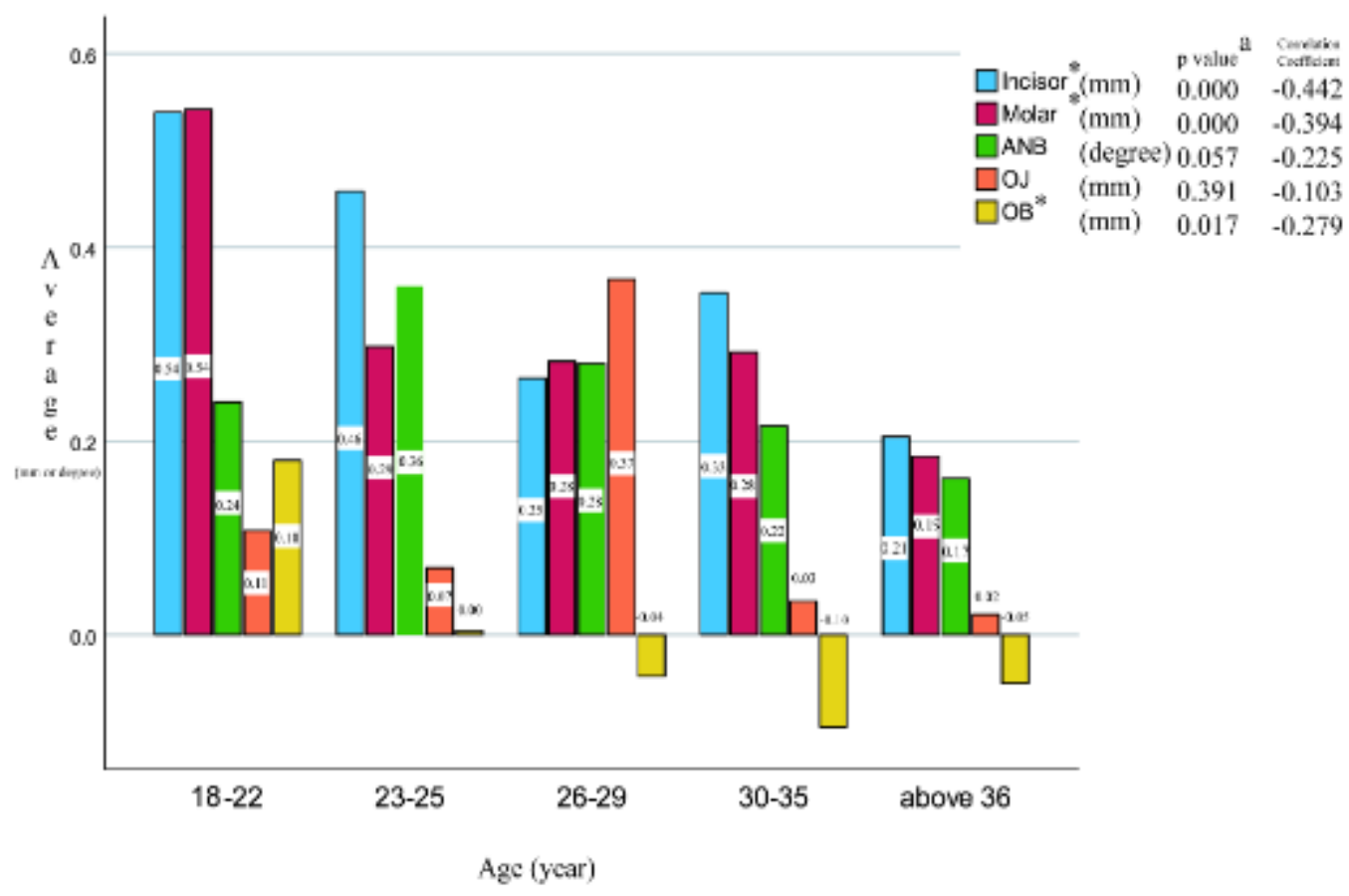

\section{Figure 3}

The correlation between the variables and the age at the operation. We confirmed a significant correlation with age for both incisor and molar. ${ }^{*} p$ value $<0.05$ was considered statistically significant. The $p$ value was calculated by Spearman analysis. 